\title{
A problemática atual do ensino de graduação em administração pública no Brasil
}

\author{
A present set of problems on Public Administration Undergraduate Courses in \\ Brazil
}

Fernando de Souza Coelho ${ }^{1}$

\section{Resumo}

Este artigo expõe e discute - a partir de evidências empíricas - algumas lacunas/limites referentes à formação acadêmica, com as quais os cursos de graduação em administração pública (AP) no Brasil se deparam na atualidade. 0 método de pesquisa utilizado foi o estudo de caso dos bacharelados em administração com habilitação em administração pública da Escola de Administração de Empresas de São Paulo (Eaesp/FGV), da Universidade Estadual Paulista (FCL/Unesp) e da Escola de Governo (EG) da Fundação João Pinheiro, de Minas Gerais, alguns dos principais cursos de graduação em AP no país desde os anos 1990. Em linhas gerais, o objetivo é jogar luz no tema; isto é, como o objeto de estudo é inexplorado, a intenção é apontar (ou gerar) hipóteses para investigações futuras. Além disso, espera-se que as informações deste estudo dêem subsídios ao debate nas instituições de ensino superior sobre os caminhos/rumos do ensino de graduação em administração pública nacional, sobretudo, neste momento de (re)definições em face das Diretrizes Curriculares Nacionais do bacharelado em administração e da extinção das suas habilitações.

Palavras-chave: ensino de graduação; administração pública; Brasil.

\begin{abstract}
This article exposes and discusses, based on empirical evidences, some gaps/limits that the Public Administration (PA) undergraduate courses face at present in Brazil. The research method consisted on the case study of the Administration undergraduate programs with emphasis on Public Administration major degree courses at Escola de Administração de Empresas de São Paulo (Eaesp/FGV), Universidade Estadual Paulista (FCL/Unesp) and Escola de Governo (EG) da Fundação João Pinheiro, Minas Gerais, some of the main AP courses in Brazil since, at least, the 1990's. Concisely, the objective is to give some lights to the theme. As the subject is unexplored in the Brazilian academic literature, the intention is to point (or generate) hypotheses for further investigations. In addition, we hope the information contained in this article supports the debate about the paths of the national PA courses in the universities, especially at this moment when (re)definitions are been made because of the Administration undergraduation National Curricular Directives and the extinction of the majors degree focus on PA.
\end{abstract}

Key words: undergraduate education; public administration; Brazil.

\footnotetext{
${ }^{1}$ Doutor e Mestre em Administração Pública e Governo pela Escola de Administração de Empresas de São Paulo da Fundação Getúlio Vargas (EAESP-FGV). Bacharel em Ciências Econômicas pela Faculdade de Economia, Administração e Contabilidade da Universidade de São Paulo ( FEA-USP - Campus Ribeirão Preto). Professor Doutor da Escola de Artes, Ciências e Humanidades - Universidade de São Paulo (EACH-USP), no Curso de Graduação de Gestão de Políticas Públicas. Endereço: Av. Arlindo Bettio, 1000 Compl. Prédio I-A Sala 302-C - Ermelino Matarazzo - São Paulo/SP - Brasil - CEP: 03828000 - E-mail: fernandocoelho@usp.br

Artigo submetido em julho de 2007 e aceito em maio de 2008
} 


\section{Introdução}

No início dos anos noventa, pessoas menos avisadas, mas muito conceituadas no mundo acadêmico da administração no Brasil, decretavam que a administração pública como disciplina estava morta [nacionalmente]. Apesar de a profecia não se ter concretizado, mostrando ser, somente, produto da desinformação e da avaliação precipitada, por outro lado, ela serve de exemplo de como a disciplina era vista no país há apenas alguns anos. (SOUZA, 1998)

A comunidade de pesquisadores em administração pública é pequena no país e corre o risco de ser auto-referida. São poucos os programas de pós-graduação stricto sensu existentes, e o fato de serem justapostos aos programas de business no sistema de pós-graduação acaba reforçando o (auto)isolamento e a identidade difusa. [...] [Essa situação] tem reflexos na formação de quadros via conteúdos dos programas de graduação e mestrado. (PACHECO, 2003)

A administração pública tem uma lógica própria, requerendo o desenvolvimento de técnicas de gestão adequadas, além de uma formação específica para os gestores públicos. Isso desafia os governantes e pesquisadores a realizarem uma combinação entre a administração e a política, humanizando o management e preservando o caráter crítico das ciências sociais. (PAES DE PAULA, 2005)

No Brasil, não se completou o ciclo das burocracias weberianas meritocráticas, nem criaram raizes as comunidades acadêmicas de administração pública e políticas públicas. Como promover simultaneamente um acerto de contas com o passado, o enfrentamento do presente e os desafios de um futuro cada vez mais precoce é o dilema a ser equacionado. (GAETANI, 1999)

Por essas citações, nota-se que diversos estudiosos da administração pública (AP) brasileira têm apontado empecilhos/dificuldades para o desenvolvimento desse campo do saber no país, pari passu à retomada de sua agenda de ensino e pesquisa nos últimos anos. Assimetrias de informação, identidade difusa, carência de tecnologias próprias (ou adequadas) e ínfima base acadêmica são alguns dos problemas da AP - em âmbito nacional $-{ }^{1}$ como área de especulação teórica das ciências sociais aplicadas.

Naturalmente, esses e outros problemas inerentes a tal campo do saber se manifestam no ensino superior de administração pública nacional, resultando em lacunas e limites que atravancam a organização/funcionamento dos cursos, quer em nível de pós-graduação, quer em nível de graduação. Neste caso, conformação teórica e técnica, formatação e integração curricular e condição real de prática profissional são - supostamente algumas das questões em aberto que perfazem a atual problemática dos bacharelados em AP e das graduações tecnológicas (e dos cursos seqüenciais) em gestão pública no país.

Destarte, este artigo expõe/discute - à luz de evidências empíricas - os problemas com os quais o ensino de graduação em administração pública no Brasil pode estar se deparando por ocasião de seu ressurgimento nos anos recentes. Em linhas gerais, o objetivo é jogar luz no tema, a fim de provocar o debate sobre os principais obstáculos que podem ser superados - ou, ao menos, amenizados - nessa formação acadêmica, fazendo com que se avance além do seu estágio atual.

O método de pesquisa utilizado foi o estudo de caso dos cursos de Bacharelado em Administração com habilitação em AP da Eaesp/FGV, da FCL/Unesp e da EG - Fundação João Pinheiro (vide os boxes 1, 2 e 3), alguns dos principais cursos de graduação em AP no país desde os anos 1990. Em relação a esses cursos, além da análise documental de projetos pedagógicos e de relatórios de atividades, foram realizadas 14 entrevistas semi-estruturadas com alguns "sujeitos coletivos", tais como co-fundadores, chefes de departamento, coordenadores de curso e representantes discentes. Além disso, o estudo faz uso também de informações obtidas em entrevistas semi-estruturadas efetuadas na Ebape/FGV, EACH/USP, UNB e na Faculdade Pública de Paulínia (Fupespp). 


\section{BOX 1 - O Curso de Bacharelado em Administração com habilitação em administração pública da Eaesp/FGV}

O curso de graduação em administração - habilitação em AP - da Eaesp/FGV foi criado em 1969 no âmbito de um convênio estabelecido entre essa instituição de ensino superior (IES) e o governo do estado de São Paulo (Gesp). Financiado por recursos públicos estaduais - e, portanto, gratuito aos alunos -, o curso propunha-se nos tempos idos a "[...] preparar pessoas para ocupar cargos de níveis médio e alto na máquina administrativa paulista." Em 1996, o fim do convênio entre a Eaesp e o Gesp tornou o curso de AP pago. Desde então, "[... as ameaças de extinção, a baixa atração de alunos com vocação e a pouca diferenciação dos programas de ensino de AP e administração de empresas (AE) nessa IES", descaracterizaram - parcialmente - a habilitação em administração pública. Não obstante, pelas palavras da coordenadora, o curso sustenta o seu valor:

"Eu vejo vários ex-alunos daqui fazendo a diferença lá fora, no governo do estado de São Paulo, em governos municipais, no governo federal [são mais de 1.500 alunos formados desde 1972]. [Estão] realmente contribuindo a partir da formação acadêmica que receberam aqui, ainda que existam todos esses problemas. Como há poucos cursos de administração pública no país e o da GV é um dos mais antigos, eu acho que nossa instituição tem uma função importante nesse ensino. Talvez, começando na graduação e passando para a pós, ela [a GV] pode ser formadora de reformadores públicos e, às vezes, uma ação muito conseqüente de um profissional formado pela GV tem um papel de multiplicador, ainda que seja pelo seu exemplo."

Fonte: elaboração do autor, baseado em entrevistas semi-estruturadas e em documentos do curso.

\section{BOX 2 - O Curso de Bacharelado em Administração com habilitação em administração pública da FCL/Unesp}

O curso de bacharelado em administração com habilitação em AP da Unesp, campus Araraquara, foi concebido no triênio 1986-1988 por professores - na ocasião - dos departamentos de economia e de antropologia política da Faculdade de Ciências e Letras (FCL) dessa universidade. Implantado em 1989, o curso objetivava no seu estágio inicial "[...] formar um profissional de gestão pública especialmente qualificado para o trato das questões municipais." Após a formatura de sua $1^{\underline{a}}$ turma (1992), iniciou-se a organização do departamento de administração pública que, dois anos mais tarde, levou a cabo uma reestruturação curricular, acatando a Resolução nº 2 do CFE de 1993 - Currículo Mínimo de Administração. Enfim, em 1995, o curso fora reconhecido pelas autoridades educacionais. Bipolarizado pelos departamentos de administração pública e de antropologia política da FCL/Unesp, o bacharelado em AP desta IES ainda ressente-se de uma falta de identidade. Apesar disso, no entender da vice-coordenadora, o curso tem contribuído para o ensino de AP no país:

"Acho que estamos ajudando a formatar esse ensino no pais. Tudo o que fazemos é para tentar definir o que é administração pública, conseguir trabalhar com isso e buscar construir esse campo, em termos de formação profissional e de pesquisa, em nível de graduação. Essa é a busca de todos nós, inclusive, dos alunos que têm muitas dúvidas e inclusive sempre perguntam o que vai ser do amanhã. Mas eu penso que só o fato de estarmos aqui pensando essas questões é algo fundamental. Estamos aqui procurando formar quadros para pensar o Estado, o governo [...]." [desde 1992, o curso graduou quase 600 bacharéis].

Fonte: elaboração do autor, baseado em entrevistas semi-estruturadas e em documentos do curso. 


\section{BOX 3 - O Curso de Bacharelado em Administração com habilitação em administração pública da EG/FJP}

O curso de bacharelado em Administração com habilitação em AP da Escola de Governo da Fundação João Pinheiro foi instituído em 1994 com o propósito de "[...] constituir-se em instrumento estratégico para a modernização do serviço público mineiro". Trata-se de um curso superior único (e inovador) no país, orientado para a formação acadêmica de profissionais que integrarão, depois de graduados, uma carreira de Estado, a de especialista em políticas públicas e gestão governamental (EPPGG) do governo do estado de Minas Gerais. Além disso, o ensino é gratuito e os alunos que não são servidores públicos recebem, mensalmente, uma bolsa de estudos correspondente a um salário mínimo. Com o 'fim das habilitações' do bacharelado em Administração - Resolução CNE no 4 de 2005 -, o curso da EG/FJP foi o primeiro curso de graduação em Administração com habilitação em AP do país a se transformar em um curso de Administração Pública. De acordo com o seu coordenador,

"[...] o curso [de graduação da FJP] é concebido, na verdade, como um ramo aplicado da ciência política, interagindo, conversando, dialogando com os instrumentos da administração pública, tendo em vista permitir que os egressos tenham uma boa capacidade de interpretação das instituições políticas na vivência do dia-a-dia na máquina estatal e, também, que tenham percepção da importância que se conquistem os objetivos das politicas de Estado que necessitam ser implementadas numa perspectiva técnica."

Entre 1997 e 2005, a EG/FJP formou 330 administradores públicos, dos quais 213 estão alocados na carreira de EPPGG. As estatísticas da Secretaria de Planejamento e Gestão (Seplag) do Estado de Minas Gerais mostram que, em média, dois terços dos egressos permanecem na carreira depois de cumprido o tempo mínimo de dois anos exigido por lei. Os que abdicam dela após o período compulsório, normalmente, se dizem insatisfeitos com a remuneração e costumam migrar, via concurso público, para as carreiras de nível federal.

Fonte: elaboração do autor, baseado em entrevistas semi-estruturadas e em documentos dos cursos.

Quanto à abordagem do texto, este artigo é um panorama ligado à busca de maior familiaridade com o assunto. Portanto, o alcance pretendido é o levantamento de informações sugestivas, sem a preocupação explícita com uma análise de relação causa/efeito. Em outras palavras, como o objeto de estudo é inexplorado, a intenção é gerar hipóteses que possam ser testadas por investigações futuras.

\section{Exposição e discussão dos resultados}

Dos estudos de caso levados a cabo, infere-se que o ensino de graduação em administração pública no país enfrenta atualmente vários obstáculos, enumerados na figura 1. 


\section{Figura 1}

Principais obstáculos ao ensino de graduação em administração pública no Brasil nos dias atuais

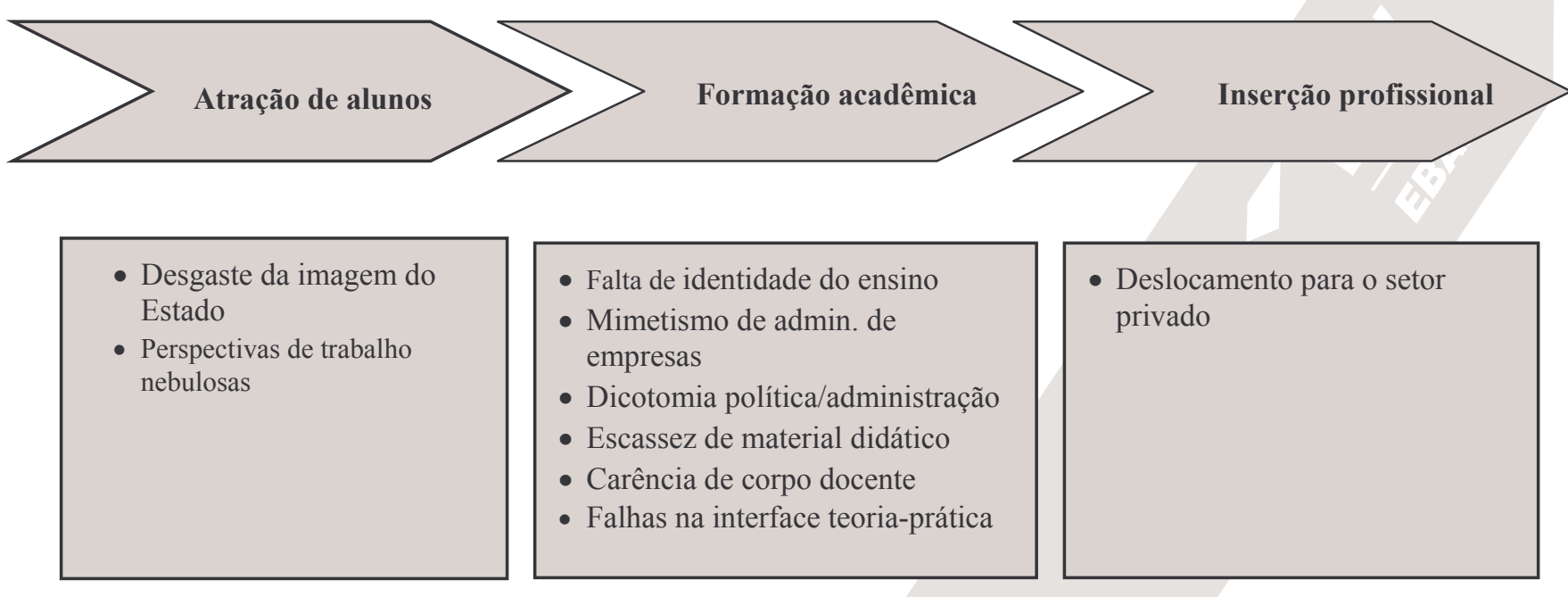

Fonte: elaboração do autor, baseada no estudo de casos.

Esses obstáculos serão detalhados em subseções a seguir.

\section{Desgaste da imagem do Estado}

Certamente, o desgaste da imagem do setor público-estatal (e do serviço civil) no país é um fatores que desestimulam os alunos dos cursos de graduação em administração pública. Pelo senso comum, o Estado brasileiro "desde sempre" está desmoralizado e é sinônimo de ineficiência, desperdício, corrupção, morosidade, clientelismo e improdutividade.

Para uma professora da Eaesp, "[...] o descrédito do serviço público ajudou a acentuar a imagem perante os estudantes universitários de que a administração de empresas é o pólo de eficiência, enquanto a administração pública seria o oposto disso." (Entrevista realizada pelo autor). Agravada no início dos anos 1990, tal descrença pôs em dúvida até mesmo o mérito do ensino superior de AP país, como revela o testemunho de um dos professores co-fundadores do curso da Unesp:

[...] Propor um curso de administração pública naquele momento [1988-1996] de crise do Estado não foi tarefa fácil. Nós acreditávamos no novo Estado democrático, mas a idéia de gestão pública [na acepção sociocêntrica] ainda era um pouco vaga. Em 1991, dois anos depois do curso ser implantado, enquanto discutíamos a primeira reforma curricular, assistíamos ao enxugamento da máquina estatal e ao esfacelamento das instituições políticas desferidos pelo governo Collor. [...] Era complicado, em pleno Consenso de Washington, você retomar a discussão do Estado, [então,] a gente se passava um pouco como visionário no âmbito da universidade. Perguntas do tipo "para que serve esse curso?" eram comuns. [...] Mantivemos nossa proposta. Em meio à crise fiscal, ao processo de privatização e ao desmonte administrativo no governo federal, procuramos focar os municípios. Achamos que era importante resgatar esse nível de governo diante do processo de descentralização em curso.

$\mathrm{Na}$ atualidade, os escândalos constantes de corrupção e o descaso (além da precariedade) de alguns serviços públicos, midiaticamente veiculados para a sociedade brasileira como se fosse o retrato fiel do conjunto da gestão pública, reforçam a idéia de que não existe competência política e capacidade administrativa no âmbito do poder público. Resultado: o ceticismo em relação ao Estado oriundo dessa desvirtuada generalização, além de dar uma conotação pejorativa para a formação acadêmica em administração pública aos olhos dos leigos, pode induzir os menos informados a pensarem que a AP nem mesmo exista como área de ensino e pesquisa. 
Em suma, os estereótipos em torno do Estado, em geral, e do serviço público, em particular, concorrem para a relativa desvalorização social dos cursos de graduação em administração pública no país, dificultando, por sua vez, a atração de alunos.

\section{Perspectivas de trabalho nebulosas}

Ainda que a alta taxa de desemprego estimule a procura pelo emprego público no Brasil, as nebulosas perspectivas de trabalho na área de administração pública, possivelmente, representem um desestímulo à entrada de novos alunos nos cursos superiores de AP (e correlatos). Sobre tal empecilho, um professor da Ebape conjectura:

[...] hoje em dia, é dificil para um jovem entrar numa escola de administração entusiasmado para estudar administração pública, visto a falta de oportunidades claras de desenvolvimento profissional. Os próprios pais, que por vezes são funcionários públicos, desestimulam o filho. Tudo o que está aí conspira por fortalecer o lado da administração de empresas, onde o campo de trabalho é mais nítido e atraente.

Além da incerteza do concurso público, contribuem para essa "nebulosidade" tanto a assimetria de informação dos alunos em relação ao mercado de trabalho real (e potencial) em administração pública, como as falhas senão a falta - de divulgação sobre a função/aplicação da formação acadêmica nesse campo do saber. A respeito disso, Cunha (1981) já afirmava:

Quando estudantes de medicina freqüentam uma universidade, sabem que após a conclusão de seus cursos, estarão qualificados como médicos. Similarmente, os estudantes de direito, de economia sabem o que estudarão [...]. Entretanto, os estudantes de administração pública não sabem ao certo o que esperar de seus cursos ou para que esses estudos os qualificarão. (Ibidem, p.30)

No entanto, se as perspectivas de trabalho no setor público são nebulosas (e a imagem do Estado está desgastada), o que explica a alta relação candidato/vaga ${ }^{2}$ no processo seletivo dos cursos de Bacharelado em Administração com habilitação em AP da Eaesp, da Unesp e da FJP?

[...] [Na Eaesp] o x da questão está no vestibular, pelo fato de entrarem os primeiros colocados, independente da opção [por AE ou por AP]. Em média, dos 50 alunos ingressantes, 40 queriam cursar administração de empresas e ficam em administração pública, porque a EAESP-FGV é um negócio maior que isso. Então, você já tem $80 \%$ da sala que olha a finalidade daquele curso como "ah, eu vou fazer esse curso só porque estou na GV". O certo seria a escola separar o joio do trigo, diferenciar os vestibulares, atraindo alunos com maior aptidão para o Curso de AP. (EX-ALUNO DA EAESP)

[...] [Na Unesp] um dos pontos que atrai o aluno é a gratuidade, mas ele não tem muita clareza sobre o que significa fazer um curso de administração pública. A grande maioria entra aqui não pela habilitação em administração pública, mas pelo fato de ser um bacharelado em administração. Muitos dizem que, como não passaram na FEA, na GV, optaram por fazer Unesp. (PROFESSORA DA UNESP)

[...] [Na FJP] a impressão que a gente tem é que os alunos são atraídos pela vinculação "curso/bolsa/carreira". Além de não pagar pelo estudo, o aluno recebe uma bolsa mensal, e, depois da formatura, tem a garantia de uma carreira. Isso não quer dizer que não haja alunos interessados na temática da administração pública, mas há aqueles alunos indiferentes que são seduzidos por esses beneficios. (PROFESSOR DA FJP)

Assim, tanto o fator "gratuidade" (no caso da Unesp e da FJP) quanto a pequena distinção (concreta e simbólica) entre estudar administração pública e estudar administração de empresas em nível de graduação são razões críveis que explicam a grande procura por esses cursos.

Talvez, nos próximos anos, o avanço da profissionalização do serviço público e o desfazimento da velha associação restritiva entre a profissão de administrador público e a ocupação de cargos/funções no âmbito 
governamental (em virtude das oportunidades de trabalho no terceiro setor e na iniciativa privada) criem uma "demanda real" pelo ensino superior de administração pública nacional. Essa é a expectativa de um professor da Ebape.

[...] Na medida em que há uma maior atenção para a gestão pública enquanto politica pública na agenda governamental, certamente, isso repercutirá [no futuro] nas escolas de administração. Mais cedo ou mais tarde, deve aumentar o número de alunos interessados em trabalhar com as "questões públicas", seja no Estado, no terceiro setor ou mesmo nas organizações privadas. A vitalidade de qualquer curso da área de ciências sociais aplicadas está muito correlacionada com o que acontece no nível da prática. Se a prática é frágil, o campo acadêmico também é. Aqui [no Brasil] a práxis da gestão pública está crescendo, os "espaços públicos" estão se ampliando, e [nesse movimento] acredito que os cursos de administração pública ganharão novo vigor.

Todavia, a continuidade do ensino de administração pública no país, em nível de graduação, está condicionada ao apoio direto do Estado, para que haja um estímulo tanto à oferta de vagas quanto à procura pelas mesmas: sem Instituições de Ensino Superior (IES) públicas e/ou subsídios, tal ensino corre o risco de não se sustentar academicamente, e sem horizonte profissional na máquina pública - além de uma boa imagem do serviço civil -, fatalmente, os cursos de AP não conseguirão atrair alunos com vocação.

\section{Falta de identidade do ensino}

A falta de identidade do ensino de graduação em administração pública no país é o obstáculo - concernente à formação acadêmica - que, de imediato, é verificado no estudo de casos dos cursos de Bacharelado em Administração com habilitação em AP da Eaesp e da Unesp. Nessas IES, a indefinição quanto ao papel e ao formato do curso é admitida com naturalidade por professores e alunos.

Sou uma defensora do Curso de AP na escola, mas eu acho que não temos, de fato, um curso de formação em administração pública, na graduação. Nem pelo lado da escola, nem pelo lado dos professores, nem pelo lado dos alunos e nem pelo lado do currículo. Assemelha-se a um Frankenstein, algo dificil de se definir com clareza. (PROFESSORA DA EAESP)

Apesar de termos entrado num curso de administração pública, na hora em que se tem contato com as matérias, entende-se que a variação para o curso [de administração] de empresas é muito pequena. Em termos de disciplina, é a troca de uma matéria ou outra - política II, direito administrativo, políticas públicas; uma coisa ou outra isolada. Nas disciplinas de administração, a única diferença é a nomenclatura, pois o conteúdo é idêntico ao do Curso de Administração de Empresas. Sistematicamente, nada que caracterize de forma plena um curso de administração pública. (EXALUNO DA EAESP)

[...] Quando cheguei aqui [em 1995] eu senti que o curso era um ajuntado de disciplinas sem uma diretriz, sem um caráter definidor, mesmo diante da boa reforma curricular que fizeram em 1994. [Ainda hoje] eu costumo dizer que o nosso curso não tem uma personalidade clara. Somos um curso ainda em busca de uma identidade. A nossa expectativa é que essa identidade comece a ser construida a partir de agora [2006] no processo de ajustamento às novas diretrizes curriculares do MEC. (CHEFE DE DEPARTAMENTO DA UNESP)

[...] O nosso curso não tem um rumo. Estamos formando um administrador público, mas não conseguimos definir quem é esse administrador público e onde ele vai trabalhar. É um curso sem identidade, um pouco "solto", sendo apenas um misto de matérias. Fica muito a cargo do aluno "correr atrás". Temos que ter muita iniciativa aqui dentro. (ALUNO DA UNESP)

Na FJP, porém, as características da IES - dentro de uma escola de governo - e a peculiaridade do curso voltado para uma carreira de Estado -, segundo a superintendente, engendram uma identidade no Curso Superior de Administração Pública (Csap). 
[...] Por sermos uma escola de governo, o norte está dado. Não estamos formando as pessoas para o "mundo", mas sim para uma carreira de Estado, com uma profissiografia bem definida. O vínculo ensino/carreira cria, naturalmente, um ethos de administração pública. Além disso, temos mecanismos de checagem da aderência do curso com as necessidades da máquina administrativa. Nosso termômetro é o desempenho dos egressos [no governo mineiro].

Essa falta de identidade do ensino de graduação em administração pública detectada nessas IES, salvo na FJP e extensível, hipoteticamente, às novas IES -, decerto, está vinculada à problemática existencial desse campo disciplinar no Brasil. Na medida em que a AP não possui jurisdição sobre um nítido corpo de conhecimentos, sua transmissão em termos educacionais é objeto de controvérsia, gerando ambigüidade e indeterminação no seu rol de formação acadêmica.3

Logo, neste momento de ressurgimento dos cursos de graduação em AP (e correlatos), necessário se torna conceituar o que é administração pública; uma delimitação do campo do saber de AP, ainda que ampla, mas sem evitar os dois termos: "administração" e "pública". À luz da experiência internacional, uma das demarcações indicadas para a disciplina de AP no Brasil é a confluência entre análise organizacional e políticas públicas.

A ausência ou indefinição de "bordas" disciplinares nesse ensino superior pode levar as IES a se valerem de uma gama de designs de cursos e matrizes curriculares, corroborando a sua descaracterização (e fragmentação) no país. Como veremos a seguir, o mimetismo de administração de empresas é uma das barreiras para a (re)identificação do ensino de graduação em administração pública nacional.

\section{Mimetismo de administração de empresas}

Segundo Coelho (2006), o ensino superior de administração pública no Brasil, durante seu 1ํㅜ ciclo (1952-1965) teve, claramente, uma identidade disseminada pela então Ebap/FGV (em 2001, a escola mudou de nome para Ebape), afinada com uma concepção de Estado e com os contornos de seu campo de saber. Isso o diferenciava da formação acadêmica em administração de empresas. No entanto, tal identidade se diluiu no decorrer de um $2^{\text {o }}$ ciclo (1966-1982). Nesse período, o enforcement do currículo mínimo de administração - com lógica de administração de empresas (AE) -, a partir de 1966, a diluição do ethos de administração pública no país - com a gestão empresarial se sobrepondo ao "Estado Empresa" - e, nos anos 1970, o milagre econômico - com o conseqüente boom do ensino de AE - corroeram a especificidade dos cursos de graduação em AP no país.

Naquele momento, a partir da junção com o ensino de administração de empresas nas IES nacionais, o ensino de graduação em administração pública se tornou uma adaptação daquele, perdendo sua dimensão instrumental/profissionalizante. De certo modo, essa situação se mantém nos dias atuais, entre outros fatores, como um efeito perverso do fato de que por quase 40 anos vem sendo mantido um currículo mínimo de administração com viés de $\mathrm{AE}$. Um dos males acarretados por tal situação é o mimetismo de administração de empresas no conteúdo programático dos cursos superiores de administração pública, quer pela organização do ensino de AP em conjunto com o ensino de AE em algumas IES, quer pela carência de tecnologia administrativa própria (ou adequada) à gestão pública.

\section{A organização do ensino de $A P$ em conjunto com o ensino de $A E$}

"Programas mistos ou conjugados de AP e AE têm resultados perniciosos inerentes ao empreendimento em si ou, por vezes, em conseqüência de circunstâncias mesológicas." Essa é a conclusão de um paper escrito em 1965 por Dwight Waldo (apud WAHRLICH, 1967, p.252), professor e pesquisador norte-americano da área de administração pública. Seu estudo mostrou que em diversas instituições de ensino dos EUA que conjugaram o ensino de AP com o de AE na década de 1950, ocorreu a "morte" da AP, por falta de nutrição (ou o enfraquecimento dela, por falta de atenção), em decorrência da própria noção de mercado. Tal fato é relatado, também, por um professor da Ebape que cursou seu mestrado em administração pública nos EUA nos anos 1970. 
[...] Nos EUA, eu conheci vários programas de administração pública que, depois que se juntaram com o [programa] de business, alguns anos mais tarde, foram descontinuados. O lado da administração de empresas tomou conta completamente, por razões financeiras, razões de preferência dos alunos, de interesses corporativos de professores etc. Hoje, na Ebape, essa é a questão. A escola mudou de nome, é "administração pública e de empresas". Estamos unificando os ensinos [de AP e de AE]. Então, qual é o futuro? Essa "pública" vai virar um adorno? A Ebape vai se transformar em um centro de pesquisa voltado à gestão empresarial, ou não?

No Brasil, o caso da Eaesp - atualmente - é esclarecedor dos "resultados perniciosos" que a organização sob um mesmo "teto" dos ensinos de graduação em administração pública e de empresas pode acarretar para o primeiro. A prevalência do lócus empresarial nessa IES, invariavelmente, acaba encobrindo (ou desfigurando) as categorias da gestão pública.

Nosso curso de [graduação em] administração pública tem uma enorme dificuldade de ter a sua identidade claramente estabelecida, por ter nascido dentro dessa hegemonia [da administração] de empresas, não só na instituição Eaesp, mas na relação Eaesp com São Paulo. A escola é vista como um patrimônio do empresariado paulista, está a uma quadra e meia da avenida Paulista e a duas da Fiesp. No ambiente da escola, o "lugar" da administração pública é reduzido, o que afeta fortemente o desenho acadêmico do Curso de AP. Além disso, a maneira como a GV é vista em São Paulo é de uma excelente escola [de administração] de empresas. Ela é identificada como uma porta promissora para a área empresarial; então, o jovem de 17 anos vem, inclusive, com uma expectativa da família para entrar aqui e fazer sucesso na iniciativa privada. Diante dessa hegemonia [da AE], ela [a GV] é pouco conhecida como tendo uma habilitação para a área de administração pública. (PROFESSORA $D A$ EAESP)

Nesse contexto é que o mimetismo de administração de empresas se manifesta:

Há disciplinas que têm uma ementa adequada, mas o professor ministra um programa completamente diferente voltado para a administração de empresas. Os exemplos são muitos e envolvem disciplinas de todos os departamentos da escola. Nós temos um grupo de professores interessados em administração pública, comprometidos, e que entram em sala de aula para dar o conteúdo previsto de administração pública. Mas a grande maioria não é assim. Além disso, muitas disciplinas não têm um programa desenhado especificamente para a área de [administração] pública. (PROFESSOR DA EAESP) 5

Muitas vezes, de forma explícita ou implícita, muitos dos conhecimentos em administração pública eram negligenciados ou ignorados [pelos alunos], a ponto dos professores repensarem o conteúdo programático de suas disciplinas. Muitos [professores] também não tinham grande interesse em AP, sendo mais divertido falar de um caso empresarial. Alguns até desdenhavam do contexto governamental. (EX-ALUNO DA EAESP)

No desenrolar do curso, há algumas matérias que dão ênfase em [administração] pública, fato esse que é muito bom. Outros [professores] jogam a decisão na mão da sala que, por razões óbvias, acabava escolhendo o enfoque [de administração] de empresa; e outros já partem de um préjulgamento de que todo mundo quer estudar AE. (EX-ALUNO DA EAESP - 2)

Cabe salientar que certo preconceito - ou, no mínimo, desprezo - com relação ao Curso de Administração Pública se faz presente na Eaesp, realçando a imagem de que a AP é o "primo pobre" da administração de empresas. De acordo com um professor da escola, "[...] alguns alunos até entram com interesse em estudar gestão pública, mas desistem ao longo do curso, de tanto ouvir críticas ao Estado, à administração pública, visões negativas e destrutivas.". Outrossim, em jogos/gincanas discentes, alguns "gritos de guerra" satíricos pronunciados pelos alunos de AE para os alunos de AP revelam, em suas entrelinhas, o menoscabo pela área de AP dentro da escola: "AP não é GV, AP não é GV, AP não é GV [...].”; "Enquanto AP não dá dinheiro, quem faz AE vai pro mercado financeiro" (bis). 
Tomando por base o caso de mimetismo de administração de empresas na habilitação de administração pública da Eaesp - onde, aliás, as turmas de AE e AP são separadas -, é de se supor que tal situação ocorra também em outros cursos de bacharelado em administração com habilitação (ou linha de formação) em AP onde haja o compartilhamento de espaços físicos e/ou ciclos básicos com o ensino de AE. Na UNB, por exemplo, de acordo com o coordenador,

O fato do Curso de Administração Pública ser uma habilitação e partilhar um currículo mínimo com as demais [habilitações] torna o ensino [de AP] contraproducente. Nas aulas comuns [entre as habilitações], as discussões empresariais ganham maior relevância e os alunos de [administração] pública, que são a minoria, ficam sem interlocução. [Na opinião dele], o Curso de Administração Pública deveria ser um curso à parte, com maior autonomia curricular.

Talvez, a liberdade instituída pelas Diretrizes Curriculares Nacionais (DCNs) do Curso de Bacharelado em Administração - Resolução CNE n⿳o 4, de 13 de julho de 2005 -, dissociada da figura do currículo mínimo, e a possibilidade da habilitação em AP se transformar em um curso de bacharelado em administração pública, diminua o mimetismo de administração de empresas no ensino superior de administração pública. Na Fundação João Pinheiro, por exemplo, parece que as DCNs já possibilitaram algum avanço na organização curricular do Csap.

[...] O currículo mínimo colocava uma "camisa de força" na estruturação de nosso curso até a aprovação das novas diretrizes, recentemente. Nas primeiras grades curriculares [1994 e 1999], tínhamos uma ausência notável de disciplinas que tratassem especificamente de refletir sobre gestão pública. Na matriz curricular em vigor [2005], pudemos corrigir isso. (COORDENADOR DA FJP)

\section{A carência de tecnologia administrativa}

Mesmo nos cursos de graduação em AP (e correlatos) que não comungam espaços físicos e/ou ciclos básicos com o ensino de AE, é de se esperar que o mimetismo de administração de empresas ocorra em algumas matérias técnicas do campo da administração - exemplos: marketing, recursos humanos, materiais, produção/serviços - pela carência (ou falta de sistematização) de tecnologia administrativa para a gestão pública.

Para Mezzomo Keinert (1998), a ausência de um think tanks de public management no Brasil ocasiona a

[...] inexistência ou pouco desenvolvimento de tecnologia administrativa adequada às especificidades do gerenciamento público. Em termos simples, ou a gerência pública se volta para o jurídico - dentro de uma visão legalista - ou privilegia as técnicas de administração de empresas. (Ibidem, p.18)

$\mathrm{Na}$ interpretação de um professor da Ebape,

A pouca produção científica na área de public management [no pais] é uma complicação para o nosso ensino de administração pública. Com a falta de pesquisa no entorno público, as pessoas estão convencionadas a pensar que técnica administrativa é a mesma coisa que administração de empresas, como se o focus administrativo se restringisse ao lócus de [administração] de empresas. [...] Um dos problemas é que muitos indivíduos que entendem disso, que têm contribuições a dar ao public management, não tem tempo para produzir intelectualmente, não tem tempo para escrever, não tem tempo para fazer coisas que dão pontos lá na Capes. As pessoas que têm uma competência nessa dimensão da administração pública, como são poucas, acabam sendo muito solicitadas fora da escola, ou pelo governo, ou pelas empresas estatais, coisas na área de extensão universitária. Essa atração é normal e até desejável. A questão é como transformar essa práxis em material de ensino. [...] O pontochave das escolas é fazer com que essa experiência prática dos docentes na gestão pública se transforme em tecnologia educacional para os cursos de [administração] pública. Se não for assim, esse imbróglio de administração pública com administração de empresas vai se manter. 
Essa conjuntura é que pode levar, por vezes, a simples e cômoda transposição conceitual de AE para AP em algumas disciplinas instrumentais dos cursos de graduação em administração pública. A seguir, a ementa da disciplina de Introdução à Mercadologia do Bacharelado em Administração com habilitação em AP da Unesp ilustra uma ocorrência de mimetismo de administração de empresas que, presumivelmente, deve se repetir em outros cursos.

Ementa: Este curso objetiva apresentar os conceitos básicos da disciplina de marketing, destacando-se: (a) a inserção estratégica de marketing nas atividades empresariais; (b) composto de marketing; (c) marketing social; e (d) temas emergentes em marketing.

Veja que a ementa não faz menção aos temas marketing governamental e marketing político-eleitoral, permeando a administração pública tão somente pela noção de marketing social. A não abordagem - ou não contextualização - da AP nessa e em outras disciplinas do referido curso é confirmada por um aluno:

Eu fiz [Introdução à] Mercadologia no semestre passado. No programa de ensino constava até uma visita técnica a uma empresa privada. A matéria era de [administração de] empresas, os exemplos eram de empresas, os estudos de casos eram de empresas. O professor dizia - "no final do curso aplicaremos os conceitos na área pública". Na hora de jogar [os conceitos] para a área pública, nós não conseguimos porque tinha acabado o semestre. Em Recursos Humanos o curso está terminando [neste semestre]; sei tudo sobre seleção e recrutamento nas empresas e não sei nada sobre concurso público, por exemplo. Em [administração de] materiais não estudamos compras governamentais; $e$ assim vai.

Diante dessa distorção no ensino de graduação em AP no país, um dos desafios é:

[...] fazer que em todas as disciplinas [do curso], o aluno seja exposto às questões da área pública. Seja de que campo for, de administração, ciência política, economia, direito, elas [as disciplinas] deveriam trazer sua formação vertical, suas raizes, mas dialogar com o aluno, de forma que aquela perspectiva possa ser aplicada na busca de soluções, de resoluções de problemas vividos por uma organização pública ou por uma rede de organizações públicas, por relações intergovernamentais ou arranjos público-privados coordenados pelo Estado. (PROFESSORA DA EAESP)

Caso contrário, no tocante ao magistério de gerência pública, persistirá o deslocamento para a realidade/experiência empresarial, jogando para segundo plano a compreensão estrutural dos fenômenos administrativos inerentes ao setor público. $\mathrm{O}$ mimetismo de administração de empresas no ensino de graduação em administração pública obscurece, também, o "lado político" da gestão pública, agravando um dos problemas - históricos - da AP como área de ensino e pesquisa: a dicotomia política/administração.

\section{Dicotomia política/administração}

Nas palavras de Henry (1975), "[...] a public administration sempre sofreu do mal congênito da dicotomia política/administração, o que impediu que se definisse com mais clareza o seu focus como ciência social aplicada." (Ibidem, p.384). No Brasil, da mesma forma que nas demais nações, esse "mal" que circunda a administração pública se fez - e ainda se faz - sentir no ensino e pesquisa desse campo do saber. Grosso modo, ainda que superada a visão de AP como princípios administrativos neutros (apartados da política), ${ }^{6}$ a dicotomia política/administração subsiste ante as controvérsias entre a perspectiva substantiva de políticas públicas e a perspectiva instrumental de gerência pública - que rivalizam politicismo e tecnicismo, governança e gerencialismo, concepção e execução, know-what e know-how.

No que tange ao ensino de graduação em administração pública, segundo Coelho (2006), o engessamento de um currículo mínimo de administração (1966) e o mote tecnocrático do regime militar deixaram pouca margem para as disciplinas de ciência política. Em geral, os bacharelados em AP enfatizavam os instrumentos gerenciais - aplicáveis às empresas públicas -, olvidando-se da análise política. A área de políticas públicas, por exemplo, era objeto de estudo apenas em nível de pós-graduação. Assim, naquela época, a dicotomia 
política/administração - pelo isolamento da política - era evidente nas grades curriculares dos cursos superiores de AP.

A partir dos anos 1990, a relativa flexibilidade do novo currículo mínimo de administração (1993) e o movimento de (re)democratização do país abriram espaço para os estudos de ciência política no ensino de graduação em administração pública. Contudo, se na atualidade as matrizes curriculares dos principais cursos de AP não mais transparecem a velha dicotomia política/administração, em contrapartida, há evidências de que ela perdura na arena pedagógico-didática, até pelos problemas de comunicação/compreensão entre linguagens acadêmicas distintas. Na Fundação João Pinheiro,

[...] existe uma tensão entre administração e política; é uma tensão constitutiva do próprio objeto de estudo. Nós estamos, ao mesmo tempo, formando pessoas para pensar o Estado e para operar a máquina; perspectivas, por vezes, conflitantes. Então, a dicotomia [política/administração] aflora naturalmente no curso, pois são áreas que não falam a mesma língua, para o bem e para o mal. (PROFESSORA DA FJP)

Na Unesp, onde o Curso de AP é bipolarizado pelos departamentos de Administração Pública e de Antropologia Política da Faculdade de Ciências e Letras (FCL), a dicotomia política/administração, no ponto de vista de um professor, "[...] existe, é latente e em alguns momentos vem à tona. Há uma disputa por espaço acadêmico entre os departamentos; certa disputa pela hegemonia intelectual dentro do curso, que atrapalha a articulação do ensino." Tal dicotomia é ratificada pelo depoimento de um ex-aluno e por um documento de avaliação externa do curso.

[...] O curso era um palco de embate entre as formas de enxergar o que seria - ou deveria ser - a administração pública. De um lado, tinha o pessoal das ciências sociais discutindo os marcos teóricos de ciência política, teoria do Estado, políticas públicas, e do outro estava o pessoal de administração, focando os aspectos práticos da gestão pública. Eu acho que ele [o Curso de AP] deve ter a robusteza das ciências sociais, mas não pode esquecer do instrumental administrativo. O problema é que as ciências sociais torcem o nariz para a administração e vice-versa. (EX-ALUNO DA UNESP)

[...] O curso não explicita uma visão do conjunto. Isso denota, talvez, a necessidade de discussões coletivas mais participativas entre os departamentos, dos docentes entre si, dos docentes com os discentes, em torno da vocação da unidade para se visualizar mais claramente um projeto integrado, melhor articulado quanto ao seu papel formador e científico-social. Isso também vai se refletir em alguns aspectos relativos ao curso e às ações com a comunidade, da forma como estão sendo desenvolvidos. [...] [O curso] reflete uma concepção de formação apenas multidisciplinar (em moldes tradicionais), sem um eixo curricular unificador que permita dar sentido às matérias, orientando seus conteúdos. (DOCUMENTO DE AVALIAÇÃO EXTERNA, p.1)

Nesse caso, a dicotomia política/administração é um obstáculo à interdisciplinaridade. Sua manifestação exacerbada põe em risco o referencial epistemológico do curso - isto é, na proporção que as áreas de política e administração não dialogam entre si, o Curso de AP corre o risco de ser apenas uma justaposição de disciplinas que muito pouco contribui para oferecer uma visão harmônica e integrada do campo da administração pública. $\mathrm{Na}$ ausência de intercâmbios reais entre as matérias de política e administração no ensino de graduação em administração pública, os cursos de AP limitar-se-ão a um arranjo multidisciplinar de compartimentos disciplinares incomunicáveis. Assim, o desafio desses cursos é (re)combinar - construtivamente - esses âmbitos do saber, caminhando para uma organização mais interdisciplinar.

Portanto, parafraseando um professor da Unesp, “[...] a dicotomia entre a política e a administração [nos cursos de AP] precisa ser superada por abordagens integrativas. Porque uma leitura política, uma leitura administrativa são leituras de uma mesma realidade, mutuamente complementares e intrinsecamente dependentes no estudo da gestão pública."; ou seja, política e administração não constituem um oximoro. Por um lado, as práticas do management público não podem ser adequadamente compreendidas sem estarem colocadas no contexto político. Por outro lado, em administração pública, todos os processos administrativos são políticos, inclusive, a execução. Isso requer um administrador público (na acepção de formação acadêmica) com conhecimentos e 
habilidades para operar na fronteira entre a política e a técnica - um "especialista tecnopolítico" capaz de planejar, negociar e aproximar pessoas e interesses (muitas vezes, contraditórios), além de executar e avaliar em organizações (e redes interorganizacionais) de interesse público.

\section{Escassez de material didático}

A pequena produção de material didático específico, contextualizado para o setor público, e sistematizado a partir da práxis, também é um obstáculo no ensino de graduação em administração pública no país. Os relatos de coordenadores do Curso de AP da Unesp e do da Eaesp ilustram essa dificuldade adicional:

Essa é uma questão muito complicada. Estou falando da minha experiência, que também ocorre em muitas disciplinas: ministro as disciplinas de organização e métodos e sistemas de informação. Não existe nenhum livro de organização e métodos que se ligue com a questão da administração pública. $O$ que fazer? Eu tenho que usar um livro tradicional de organização e método com organogramas de empresas. Os manuais de áreas técnicas da administração pública são contados nos dedos. Essa é uma dificuldade na construção dos cursos; a dificuldade de bibliografia. Tem muitas coisas em inglês e não dá para trabalhar com bibliografia assim na graduação. Então, nós temos uma restrição bastante grande. [Temos] que construir essas coisas, porque se nós não temos material para utilizar em sala de aula, é porque não publicamos. Nós precisamos de outro tipo de pesquisa e de publicação para, inclusive, utilizar em sala de aula. São problemas enquanto campo e são coisas complicadas de digerir. (PROFESSORA DA UNESP)

O professor não poderia, ao tratar de sua disciplina, tentar aproximar os alunos dos desafios especificos da área pública? Então, essa seria uma visão importante nas disciplinas de administração: que você olhasse para qualquer disciplina que compõe o currículo, mesmo para aquelas que são comuns enquanto nomes [entre AP e AE] e procurasse adequá-las para o objeto especifico, para o exercício da área pública. Não de uma área pública abstrata, e sim de uma área pública contemporânea e com seus desafios. Porém, muitos se queixam da falta de bibliografia sistematizada na área de gestão pública. (PROFESSORA DA EAESP)

No Brasil, a abordagem teórico-conceitual na administração pública apóia-se, consideravelmente, em disciplinas das áreas de ciência política, sociologia e economia, entre outras, olvidando-se com freqüência da administração geral. Ademais, essas influências estão presentes, no mais das vezes, em coletâneas, papers e em artigos acadêmicos que, por força da linguagem, do conteúdo e, por vezes, da abstração teórica, reduzem significativamente o número de leitores. Nesse cenário, e na medida em que é diminuta uma bibliografia sobre o setor público na área do conhecimento da administração - referente às subáreas do marketing, de recursos humanos, produção \& operações -, conforma-se outro óbice ao desenvolvimento do ensino superior de AP.

A produção bibliográfica com conceituações e aplicações à prática administrativa de AP se concentra comumente em algumas contribuições de revistas com abordagens mais acadêmicas - como a Revista de Administração Pública (RAP), editada pela Ebape, e a revista Organização e Sociedade (O\&S), editada pela Universidade Federal da Bahia (UFBA) - ou com enfoque mais instrumental - como a Revista do Serviço Público $(R S P)$, publicada pela Escola Nacional de Administração Pública (Enap). Essas revistas estão vinculadas, portanto, a instituições que iniciaram a trajetória acadêmica da administração pública no Brasil, como o Departamento Administrativo do Serviço Público (Dasp)-Enap e a Ebap/FGV, ou que de longa data mantêm cursos de AP em nível de pós-graduação, como a UFBA.

Não obstante, ainda não se formou uma produção bibliográfica que reúna conhecimentos, estudos de caso e sistematizações abrangentes e fidedignos às especificidades do setor público e que estabeleça materiais didáticos para um conjunto das subáreas funcionais da gestão pública. Como conseqüências, apontam-se os seguintes aspectos:

Primeiro de tudo, a pouca instrumentalização do alunado para a atuação profissional. Em segundo lugar, muitas disciplinas do Curso de AP tendem a ser ministradas com materiais de apoio de AE. Assim, muitos docentes 
ficam a mercê de referências bibliográficas e casos de administração de empresas. Ainda assim, no caso da FJP, alunos entrevistados observaram:

Claro que, por haver mais literatura de administração privada, há uma introdução à administração privada nas disciplinas técnicas; mas não podemos reclamar, pois têm professores que olham para a realidade da administração pública. A falta de bibliografia atrapalha um pouco, mas a experiência dos professores na área [governamental] acaba compensando isso. (ALUNO DA FJP)

De um lado, tem-se que muitos docentes se apropriam - sem ressalvas - de materiais didáticos de AE; de outro, o processo de ensino-aprendizado depende da capacidade de docentes de disciplinas relacionadas com a tecnologia administrativa contextualizarem conteúdos de AE no ambiente organizacional e processual da administração pública.

Materiais didáticos específicos à AP tenderiam a ser incorporados na literatura exigida por concursos públicos dessa natureza. Além disso, essa lacuna bibliográfica necessita ser preenchida, de modo que haja uma identificação do leitor com a prática administrativa pública, sem que, contudo, baseie-se em frágeis conteúdos teórico-conceituais ou em simples mimetismo a partir da área de administração de empresas.

Para tanto, uma medida de mais fácil alcance seria o estímulo - por meio das instituições centrais no ensino de AP no Brasil - a que pesquisadores e docentes produzam compêndios, manuais e livros de texto. Isso se daria a partir da experiência prática que alguns tenham, pelo aproveitamento de atividades de ensino e estudos de caso já desenvolvidos no ambiente dos cursos ou, mesmo, pela sistematização de conteúdos trabalhados pelas revistas supracitadas, em particular pela RSP. Tratar-se-ia da formatação de uma literatura autóctone e voltada à prática administrativa, num esforço similar ao empreendido pela Ebap/FGV entre os anos 1950 e 1970.

\section{Carência de corpo docente}

Atualmente, o banco de dados do Inep mostra uma expansão considerável dos cursos de graduação de AP no Brasil. No entanto, esse crescimento não se faz acompanhar do surgimento de cursos de pós-graduação, essenciais para a formação de um corpo docente específico da área. Certamente, isso ajuda a explicar porque as vagas para docentes nos novos cursos foram ocupadas por profissionais de outras áreas, como ciência política, ciência econômica, administração de empresas e, menos freqüentemente, por profissionais egressos da máquina pública. No Curso de Bacharelado em Administração com habilitação em AP da Fupespp, por exemplo:

[Busca-se] professores na "máquina". Principalmente, para as disciplinas de práticas administrativas. Por sermos uma faculdade isolada, não temos tantas exigências de titulação, ainda que seja muito importante. Para nós, o peso do doutor é menor. Então a gente procura, para essas disciplinas, trazer pessoas do funcionalismo público. Nosso professor de política urbana é gestor público da prefeitura de São Carlos e dá aula aqui, uma vez por semana. O professor de habitação é secretário de Habitação da prefeitura de Campinas. O de saúde pública vem de São Paulo. Ele é consultor da prefeitura de Santo André e ajudou a reestruturar todo o trabalho dos prontos-socorros municipais e do atendimento público de saúde. Nossa professora de política educacional é secretária da Educação em Indaiatuba. Então, é nessa linha. Nós deixamos os professores doutores e mestres para as disciplinas básicas, de fundamentação. (PROFESSOR DA FUPESPP)

[...] Mas esse tipo de coisa pode mudar de uma hora para outra, não é? Não que nós queiramos mudar, mas a pessoa, às vezes, dá um ou dois anos de aula e cansa. Isso acontece muito em instituições de ensino pequenas como a nossa. As próprias exigências profissionais do dia-a-dia acabam afastando essas pessoas da docência, ou a faculdade começa a exigir dela mestrado e doutorado e ela acaba fazendo uma opção pela carreira [no mercado] e não pela docência. Você acaba tendo uma rotatividade maior de professores e isso prejudica o andamento do curso. (PROFESSOR DA FUPESPP - 2)

Ainda assim, em instituições produtoras de conhecimento, como a USP e a Unesp, constata-se uma carência de profissionais com experiência prática para atuarem no ensino de administração pública: 
[...] Imaginávamos tentar mudar a forma de contratação docente, pois para nós, não resolveria apenas a visão acadêmica, sendo necessária a presença de pessoal advindo do setor público e que de alguma maneira pudesse ser contratado, pelo menos, temporariamente. Enfim, precisávamos da participação de alguém que tivesse a vivência. Não dava para meia dúzia de pessoas da área estritamente acadêmica trabalhar na parte da gestão do setor público, por exemplo. E esse foi um problema que nós não conseguimos solucionar no início do projeto, e que hoje ainda continua. (EXPROFESSOR UNESP)

Uma coisa que temos que estar preocupados - eu como coordenador - é o perfil do corpo docente que nós vamos trazer aqui para dentro. Não adianta trazer um grande jurista, um grande cientista político, um economista de ponta, se o "cara" está preocupado exclusivamente com a sua área de pesquisa. Tem que ser um "cara" que, ao entrar aqui, dialogue e se preocupe com os problemas de políticas públicas. Esse é o ponto crítico. Você não tem tantas pessoas que vêm da máquina pública e que possam desenvolver um trabalho docente em administração pública; até porque muitos não têm formação acadêmica compatível com as exigências da universidade. O Curso de [graduação] em Gestão de Políticas Públicas é obrigado a abrir concurso público para doutores, e, nessa área, não é todo dia que você acha alguém. (PROFESSOR DA USP)

À medida que se deparam com as exigências de docentes com formação acadêmica em pós-graduação stricto sensu, muitas IES devem estar vivenciando limitações na constituição e na renovação de quadros especificamente - em administração pública. Tal fato pode se refletir em um ensino descontextualizado do paradigma da administração pública vigente (teoria) e do exercício profissional (prática). Logo, um sério ponto fraco em vários cursos de $\mathrm{AP}$, atualmente, pode ser que alunos recebam ensinamentos sobre administração pública, em vez de ensinamentos de administração pública, porque docentes, muitas vezes, não trazem conhecimento (e vivência) da práxis. Isso é constatado no depoimento de um ex-aluno da Unesp:

[...] É muito ruim você ter uma pessoa falando como funciona o Estado, como ele deve funcionar, quais são as relações que o regem, qual a legislação que o rege, se a pessoa nunca teve contato com ele no seu dia-a-dia, nunca passou por essas limitações, nunca teve que usar a criatividade e a referência a uma legislação para viabilizar determinada coisa. É interessante ver quantas vezes foi discutido o tema licitação no curso. Nós tivemos aula de administração de materiais e nunca falamos de licitação. Nós falamos, sim, na matéria de direito administrativo, mas sobre (sic) o ponto de vista da legislação.

Todavia, a experiência contrafatual - de contar com docentes com formação acadêmica combinada com extensa participação em atividades governamentais - pode ser averiguada na FJP, o que se explica pelos vínculos outrora apresentados neste artigo entre ensino superior e setor público.

A Fundação, por ser uma instituição de pesquisa do tamanho que é, sempre teve em seus quadros administradores e contadores que, de certa forma, passaram a vida inteira pesquisando, servindo, coordenando projetos de demanda do próprio Estado. Então, aproveitamos essas pessoas. E quando não, nós conseguimos trazer gerentes do Estado para lecionar. Eles trabalham como "horistas" no curso. Um exemplo nosso aqui, já clássico, desde a origem, é de uma professora [que] leciona já há uns quarenta anos [e que] tem um enorme conhecimento. É uma pessoa que coordena o orçamento do Estado há mais de quinze anos e, desde o início do curso, ela ministra algumas disciplinas. Nosso quadro docente é praticamente um misto [de ex-professores e jovens doutores] da Fafich (Faculdade de Filosofia, Ciências e Letras) da UFMG e de quadros formados na própria FJP. (PROFESSORA DA FJP)

Além da escassa oferta de formação acadêmica stricto sensu em AP e da dificuldade de se dispor de profissionais com experiência em gestão pública, o ensino de administração pública no Brasil tem, de longa data, um problema estrutural: sua prática surgiu em decorrência dos estudos de especialistas de outras áreas, e estes trouxeram consigo a perspectiva teórica de sua formação. Como conseqüência, os frágeis vínculos entre ensino e setor público contribuíram para o débil desenvolvimento de uma área que carece não apenas de 
profissionais, mas também de conteúdos de ensino que trabalhem, a contento, a administração púbica a partir de suas especificidades. Tais especificidades estão relacionadas a categoriais setoriais - como saúde, educação, habitação e transportes, entre outras - ou funcionais - como recursos humanos, marketing, administração financeira, logística e operações, entre outras.

Em resumo, é imperioso que os cursos de AP contem com docentes titulados, com dedicação em tempo integral e que alternem seus trabalhos acadêmicos com pesquisas e projetos de extensão no setor público. Esses cursos também devem dispor de professores-gestores (atuantes na gestão governamental), os quais poderiam encarregar-se de disciplinas (e oficinas) profissionalizantes, de tutorias/estágios e de seminários. Ademais, há que se buscar as especificidades da área de administração pública através de novos ou de renovados programas de pós-graduação stricto sensu.

\section{Falhas na interface teoria/prática}

Falhas na interface teoria/prática são reconhecidas, tanto pelo corpo docente como pelo corpo discente dos cursos de Graduação em Administração com habilitação em AP da Eaesp, da Unesp e da FJP. Na Eaesp, o subaproveitamento da expertise de parte do corpo docente e a falta de estágios estruturados para a habilitação em AP são alguns dos fatores determinantes de tais falhas.

A imersão no campo e os exemplos de boas práticas são muito importantes num curso de [administração] pública, inclusive, para desconstruir o preconceito que alguns alunos têm sobre o setor público. [...] Nós temos vários professores que têm e tiveram experiência riquíssima de ação junto ao governo federal, do estado e do município de São Paulo. Mas isso é, ao mesmo tempo, a nossa fraqueza enquanto curso, porque ele não está estruturado de forma a mobilizar essa vivência de nossos professores na prática. Há uma riqueza de vida no Estado e conhecimento sobre a prática governamental que o curso não consegue mobilizar. (PROFESSORA DA EAESP)

[...] Não temos programas de estágios adequados no setor público e [diante disso,] os alunos ficam desmotivados com a pouca oportunidade de exercitarem seus conhecimentos. De fato, é um grande problema encontrar bons estágios na estrutura governamental, e a escola também não se mobiliza para isso. Nossa postura é mais reativa do que proativa. (PROFESSOR DA EAESP)

Já eram poucas as disciplinas que discutiam conteúdos de [administração] pública, e para piorar a situação, não havia oferta de estágios na área pública. No Cecop (Centro de Colocação e Orientação Profissional da Eaesp), só tinha vaga em empresas [privadas] e ONGs. Quem quisesse estagiar em órgãos do governo, tinha de correr atrás, por conta própria, ou tentar participar de algum projeto da Júnior Pública (empresa júnior dos alunos de AP) na área. Agora, parece que a escola está se mexendo um pouco mais. Tem o Conexão Local,'7 o convênio com a Fundap. (EX-ALUNO DA EAESP)

Na Unesp, por sua vez, o vínculo frágil com o setor público e a insuficiência de projetos de iniciação científica e extensão acadêmica são os fatores que dificultam a interface teoria/prática.

[...] Em administração pública é vital um ensino superior que articule o "pensar" e o "fazer", que conecte a academia à realidade do Estado e até mesmo do terceiro setor. E aqui [na Unesp] essa aproximação ainda é incipiente. Então, o grande problema que a gente tem no curso é esse distanciamento da escola do dia-a-dia do setor público. Isso prejudica a formação [acadêmica] do aluno, no sentido de aplicação dos conhecimentos adquiridos. (PROFESSOR DA UNESP)

[...] Você não vê bolsas de iniciação científica e projetos de extensão aqui dentro, salvo um ou outro professor que, de vez em quando, oferece algumas oportunidades de trabalho para [auxiliar de] pesquisa. Estágio, até que não é dificil de encontrar nas prefeituras da região, mas não são remunerados. Temos que pagar a condução, e já vi casos que o aluno teve até que levar material de escritório, pois [a repartição] não tinha. Isso é desanimador. Temos a Paulista Júnior (empresa júnior dos alunos de AP) que é uma iniciativa legal, mas são poucas as vagas [oferecidas]. (ALUNO DA UNESP) 
Na FJP, por seu turno, tratando-se de uma escola de governo, as falhas na interface teoria/prática referem-se aos gaps de competência de direção e domínio ferramental.

[...] Como a carreira [de EPPGG] é assentada sobre determinadas atividades e processos no governo do estado [de Minas Gerais], por mais importante que seja problematizar o que é feito, somos cobrados pela orientação para a ação, para o conteúdo prático e para a aplicação imediata do conhecimento. Nesse aspecto, deixamos a desejar no desenvolvimento de competências de gestão. Os alunos saem daqui sem saber como estruturar uma equipe de trabalho, como gerenciar um projeto em todas as suas etapas, como negociar e interagir com atores sociais. Acabamos nos concentrando nos conteúdos e temos pouco espaço para trabalhar essas habilidades. Mas são coisas que também não sabemos muito bem como fazer. Uma maneira, talvez, seriam essas técnicas [didáticas] utilizadas por bons cursos de MBAs: simulações, jogos, estudos de casos, atividades complementares, mas que precisariam de um investimento da escola. Mas não sei se isso é um consenso. A questão é que ainda usamos uma forma de ensinar muito tradicional e precisamos repensar isso. (PROFESSORA DA FJP)

[...] Volto a falar que acho muito importante teorizar, mas muitos alunos chegam para trabalhar no Estado e ferramentas gerenciais lhes faltam. E, com o dia-a-dia, você tem que aprender isso na marra. No estágio obrigatório [dentro das secretarias], já aprendemos muitas coisas. Mas como aqui [a FJP] é uma escola de governo, acho que poderíamos ter algum contato, já nas matérias, com os instrumentos, sistemas de trabalho. [Por exemplo], no final da disciplina de administração de AFO (administração financeira e orçamentária), poderíamos conhecer um pouco do Siafi (Sistema Integrado de Administração Financeira), não é? Tem aluno que se forma, entra na carreira, chega lá na secretaria e nem sabe o que é isso. (ALUNO DA FJP)

Exceto na FJP, onde os alunos já ingressam numa carreira pública estadual durante o processo de admissão no curso, na Eaesp e na Unesp, onde há poucas possibilidades de interface teoria/prática, muitos alunos intentem iniciar nos cursos seu aprendizado prático (estágios, por exemplo) na área de AE.

$\mathrm{Na}$ verdade, assim como a inexistência de intercâmbio escola/empresa fragiliza um curso de graduação em administração de empresas, a falta de vínculo com o setor público debilita um curso de graduação em administração pública. Neste caso, a co-indução de mais estágios e projetos de extensão, atrativos e abrangentes, em órgãos público-estatais, bem como o estabelecimento (e/ou melhor utilização) da relação escola/governo são algumas ações a que as IES podem (e devem) recorrer para consolidar os cursos de AP.

Como recomendam as Diretrizes Curriculares Nacionais (DCNs) do Curso de Bacharelado em Administração, é importante nesse ensino superior - seja em AE ou em AP - que o aluno obtenha uma "visão realística da operação das organizações, suplementada, sempre que possível, por alguma experiência em processos empírico-analíticos". Para tanto, em algum ponto final, o ensino de graduação em administração pública requer uma abordagem prática que extrapole o universo da intelligentsia e permita uma compreensão do universo profissional.

\section{Deslocamento para o setor privado}

Provavelmente, alguns dos obstáculos anteriores - perspectivas de trabalho nebulosas, mimetismo de administração de empresas e falhas na interface teoria/prática - acabam por reforçar (ou ter como conseqüência) a inserção profissional dos egressos de cursos de AP no setor privado.

Além desses obstáculos, se considerarmos a acirrada concorrência (e difícil aprovação) nos concursos públicos e a falta de "capital social" e/ou experiência dos jovens para uma indicação técnica aos cargos públicos, tornase natural que a maioria dos estudantes de administração pública, em nível de graduação, concluído o curso, pleiteie vagas no mercado de trabalho empresarial.

[...] O aluno de AP sempre pensa: - Vou me formar e esperar o concurso público para a carreira x ou y? Mas será que vai haver esse concurso mesmo? E se eu for aprovado, você ser chamado? Em quanto tempo? Tudo isso é uma coisa inconcebivel para muitos alunos. [Portanto], na primeira oportunidade 
de emprego em alguma empresa [privada], o aluno já desiste do setor público. (EX-ALUNO DA EAESP)

[...] Onde posso trabalhar [no Estado]? Quem pode me indicar? Meu trabalho será reconhecido? Nesses pontos, até os mais engajados com o setor público se questionavam. (EX-ALUNO DA EAESP 2)

Atualmente, a maior abrangência do campo profíssional de administração pública permite aos egressos dos cursos da área se dirigirem para funções no terceiro setor, para atividades de "interesse coletivo" ou que envolvam relações governamentais providas pelo setor privado, que correspondem a sua formação acadêmica. Contudo, os benefícios financeiros proporcionados por outras áreas profissionais de administração dissociadas da AP exercem forte atração sobre esses egressos. 8

Hoje, além do concurso público, alguns alunos daqui têm também a idéia de trabalhar numa ONG ou numa dessas grandes empresas que têm projetos sociais. Mas a maioria quer ir mesmo trabalhar em bancos, ser [gerente] trainee de multinacional, ter remuneração variável, participação nos resultados, tocar o negócio do pai. Ah, e depois de formado, enquanto um ou outro fala de fazer um mestrado na área [de AP], o resto fala em fazer um MBA pra melhorar a formação na área de [administração] empresas. (ALUNO DA UNESP)

Há [também] um dilema trágico e que só me ocorreu há pouco tempo. Ainda que o aluno [de AP da GV] tenha vocação e ele queira mesmo trabalhar no setor público, se ele for bolsista (financiamento estudantil), ele tem que pagar a escola, e a divida é bastante alta - [se o aluno financiou os quatro anos de curso, o valor a ser pago é próximo de R\$100.000,00]. É possivel pagar? É, mas ele pensa que se for trabalhar em finanças, marketing [empresarial] etc. o êxito vai estar garantido. É claro que o concurso público abre possibilidades, inclusive, de salários maiores no início. Mas sabemos que a aprovação num concurso público é incerta. (PROFESSORA DA EAESP)

No caso dos egressos da FJP o obstáculo não é a entrada destes no Estado, mas a sua retenção na carreira de EPPGG - no governo do estado de Minas Gerais - após os dois anos exigidos por lei. A insatisfação com a remuneração e a rigidez de promoção leva alguns desses profissionais recém-formados a buscarem, por meio de concurso público, colocações em carreiras federais. Mas há também aqueles que, desmotivados com o setor público-estatal, acabam migrando para a iniciativa privada.

[...] O maior salário da carreira é $R \$ 4.000,00$; isso, em seu final. Então, não é atrativa. Mas, para os dois primeiros anos, um recém-formado ganhar $R \$ 1.800,00$ é um bom salário. Só que é uma carreira que não consegue prender as pessoas; a promoção é rígida. Quem tem disponibilidade e quem tem vontade, acaba fazendo concurso e indo embora pro governo federal. É um curso que dá uma formação muito boa; então, quem aproveita, presta concurso e vai embora. [...] Mas conheço pessoas que ficaram jogadas [na carreira] e perderam o gosto de trabalhar no setor público. Pessoas que tinham ideais, que queriam fazer algo, mas que ficavam naquele marasmo. Essas [pessoas] abrem mão da carreira e vão trabalhar em empresas [privadas]. (EX-ALUNO E PROFESSOR DA FJP)

\section{À guisa de conclusão}

Levando em conta a carência no país de estudos sistemáticos sobre o ensino superior de AP - a despeito da atualidade, pertinência e do amplo universo de interessados no assunto -, este artigo buscou contribuir não apenas para o enriquecimento da bibliografia/documentação afim, mas também para que diminua a assimetria de informação na gestão acadêmica dos cursos da área.

Sua contribuição específica repousa na categorização de alguns dos núcleos essenciais da problemática do ensino de graduação em administração pública no Brasil nos anos recentes. Dessa forma, lacunas e limitações nesse ensino, muitas vezes evidentes para os interlocutores da pesquisa (entrevistados), foram reconstituídas sistematicamente. 
No entanto, a abordagem em torno de cada categoria - no caso, os obstáculos apontados - requer aprofundamentos, via descrição exaustiva dessas ocorrências ainda pouco encaradas como objeto de estudo. Digam-se ocorrências em vez de intercorrências porque se trata de problemas em sua maioria crônicos, a saber: dicotomia política/administração, carência de corpo docente e escassez de material didático. Esses são obstáculos do passado que permanecem no presente. A Ebap (hoje Ebape), por exemplo, como a pioneira e mais destacada IES de administração pública no país entre os anos 1950 e início dos anos 1980, já se deparava com algumas dessas dificuldades.

A emergência de novos cursos de graduação em AP no país nos últimos anos é uma oportunidade para se intensificar o debate sobre os problemas do ensino nessa área. Afinal, levar adiante essa discussão, certamente, permitirá uma melhor definição das especificidades da administração pública como campo disciplinar, ampliando conhecimentos e possibilitando um entendimento mais amplo das necessidades do mercado de trabalho.

Esse processo pode ser irradiado pelas escolas tradicionais - Ebape, Eaesp, UFBA, Unesp, Fundação João Pinheiro e, mais recentemente, pela Universidade do Estado de Santa Catarina (Udesc) - no ensino de administração pública no Brasil, conformando-se redes acadêmicas ${ }^{9}$ com o intuito de: construir uma filosofia explícita e clara nesse ensino, produzir referências bibliográficas adequadas às várias realidades em que os cursos superiores de AP estão inseridos, capacitar corpo docente para lidar com as particularidades da área e ensejar vínculos com o setor público. 


\section{Referências}

ANGRAD - Associação Nacional dos Cursos de Graduação em Administração; CFA - Conselho Federal de Administração. Diretrizes curriculares nacionais para o Curso de Graduação em Administração. Brasília, DF, 2005. Mimeografado.

CAVALCANTI, B. Formação do administrador público: alternativas em debates. Revista de Administração Pública. Rio de Janeiro, FGV: 15(3): p. 31-53, jul./set. 1981.

A gestão pública como componente do desenvolvimento curricular das escolas de administração. Revista de Administração Pública. Rio de Janeiro, FGV: 18(4): p. 42-57, out./dez. 1984.

A gestão pública integrada: implicações para a formulação de teorias, modernização administrativa e ensino de administração pública. Revista de Administração Pública. Rio de Janeiro, FGV: 25(3): p.173-184, jul./set. 1991.

CHETKOVICH, C. What's in a sector? The shifting career plans of public policy students. Public Administration Review. Washington, ASPA: 63(6), p. 660-674, nov./dec. 2003.

COELHO, F. Educação superior, formação de administradores e setor público: um estudo sobre o ensino de administração pública - em nivel de graduação - no Brasil. Tese (Doutorado) - Escola de Administração de Empresas de São Paulo, Fundação Getulio Vargas, São Paulo, 2006. Mimeografada.

CUNHA, A. Educação em administração pública: retrospectiva e perspectivas da experiência norte-americana e reflexões sobre o caso brasileiro. Revista de Administração Pública. Rio de Janeiro, FGV: 15(3): p. 54-69, jul./set. 1981.

FISCHER, T. 0 ensino de administração pública no Brasil: os ideais de desenvolvimento e as dimensões de racionalidade (1948-1984). Tese (Doutorado) - Faculdade de Economia e Administração, Universidade de São Paulo, São Paulo, 1984. Mimeografada.

GAETANI, F. 0 ensino de administração pública no Brasil em um momento de inflexão. Revista do Serviço Público. Brasilia, ENAP: 50(4): p. 92-120, out./dez. 1999.

HENRY, N. Paradigms of public administration. Public Administration Review. Washington, ASPA: 35(4), p. 378-386, nov./dec. 1975.

MEZZOMO KEINERT, T. Do aparelho estatal ao interesse público: crise e mudança de paradigma na produção técnico-científica em administração pública no Brasil (1937-1997). Tese (Doutorado) - Escola de Administração de Empresas de São Paulo, Fundação Getulio Vargas, São Paulo, 1998. Mimeografada.

PACHECO, R. Administração pública nas revistas especializadas - Brasil, 1995-2002. Revista de Administração de Empresas. São Paulo, FGV: 43(4), p. 63-71, out./dez. 2003.

PAES DE PAULA, A. P. Administração pública brasileira entre o gerencialismo e a gestão social. Revista de Administração de Empresas. São Paulo, FGV: 45(1), p. 36-52, jan./mar. 2005.

SOUZA, C. Pesquisa em administração pública no Brasil: uma agenda para o debate. Revista de Administração Pública. Rio de Janeiro, FGV: 32(4), p. 43-61, jul./ago. 1998.

WAHRLICH, B. Formação em administração pública e de empresas: programas específicos ou integrados numa sociedade em desenvolvimento. Texto para Discussão. Rio de Janeiro, FGV, 1967. Mimeografado.

Notas explicativas

1 Salienta-se que a administração pública como disciplina sofre limitações conceituais e metodológicas na maioria dos países, inclusive nos EUA, sua pátria-mãe. Em contrapartida, é notório que os problemas enfrentados pela área acadêmica de AP no Brasil são mais amplos e profundos do que aqueles que afligem os norte-americanos, sobretudo, em decorrência da inconstância histórica (e da relativa juventude) desse campo disciplinar em nosso país.

${ }^{2}$ No ano de 2005, 12 alunos/vaga na Eaesp, 19 alunos/vaga na Unesp e 31 alunos/vaga na FJP.

3 Para GAETANI (1999), dois elementos contribuem para manter o campo acadêmico de administração pública no Brasil como um "sistema aberto", a saber: sua difusa base de conhecimentos e sua problemática jurisdição. O primeiro elemento resulta da natureza interdisciplinar da AP (e das complicações inerentes para codificá-la). Já o segundo elemento decorre da carência de credenciais acadêmicas e da insuficiência de um corpo de conhecimentos sistematizados capazes de conformar uma disciplina autônoma de AP no país.

${ }_{4} \mathrm{Na}$ Ebape, o Curso de Bacharelado em Administração (retomado em 2002) oferece aos alunos, no último ano, a possibilidade de escolherem entre um currículo que enfatize a $\mathrm{AE}$ e um currículo que enfatize a AP. Na primeira turma, dos 40 alunos, 36 optaram pela ênfase em AE e quatro, pela ênfase em AP.

5 Analisando o projeto pedagógico do curso de graduação em Administração (ADM), habilitação em AE e AP, da Eaesp (versão 2004), constata-se facilmente que as ementas (e programas) de diversas matérias obrigatórias do curso de AP não têm como foco a área 
pública. Outra evidência do mimetismo de administração de empresas na habilitação de AP é a escolha das "trilhas" eletivas e das disciplinas optativas. Nesse caso, comumente, os alunos de AP optam pelas ofertas da área de AE.

${ }^{6}$ Refiro-me à visão tradicional (ou ortodoxa) da administração pública, iniciada por Woodrow Wilson e disseminada pela escola clássica scientific management - no setor público.

7 O Conexão Local é um projeto de estímulo à iniciação científica aplicada, direcionado aos alunos de graduação da Eaesp e coordenado pelo GVpesquisa e pelo Programa Gestão Pública e Cidadania. O objetivo geral desse projeto é aproximar os alunos das diversas realidades brasileiras por intermédio de viagens de imersão que acontecem durante o mês de julho. Entre os objetivos específicos, 0 projeto visa: (i) favorecer o conhecimento prático de técnicas de gestão pública em regiões e contextos os mais variados e complexos e (ii) promover a troca de saberes entre os alunos, os gestores públicos e as comunidades.

${ }^{8}$ Mesmo nos EUA, onde o campo profissional de public administration é extenso e vigoroso, os concluintes dos cursos de graduate em public policy/management têm se "deslocado" para o setor privado. (Ver CHETKOVICH, C., 2003).

9 Atualmente, a única rede acadêmica no ensino de graduação em administração pública no país é a que gira em torno do Eneap (Encontro Nacional de Estudantes de Administração Pública), formada pelo corpo discente dos cursos de AP da Eaesp, Unesp, FJP e Udesc. Criada em 2002, por iniciativa dos alunos da Unesp, essa rede organizou, desde então, sete grandes encontros anuais, congregando estudantes de vários cursos superiores de administração pública para debater os temas e rumos dessa formação acadêmica no Brasil. 